\title{
How Will the Digital Tools Change Healthcare?
}

\author{
Chiweon Kim \\ Seoul Wise Geriatric Hospital, Uiwang, Korea \\ 디지털 헬스케어는 의료를 어떻게 바꿀 것인가? \\ 김 치 원 \\ 서울와이즈재활요양병원
}

Received November 6, 2019 Revised December 16, 2019 Accepted December 18, 2019

Address for correspondence Chiweon Kim, MD, MPh Seoul Wise Geriatric Hospital,

101 Anyangpangyo-ro,

Uiwang 16001, Korea

Tel: +82-31-422-1991

Fax: +82-31-423-0093

E-mail: chiweon@gmail.com
Digital technology has transformed our lives. Healthcare is not an exception. Many devices have showed up in various areas of healthcare to offer new value. The first area affected is diagnostics. New devices in combination with smartphones make it possible to perform tests at home that would have been done only at hospitals. The diagnostic tests may lead to treatment in everyday life. Several medical apps called 'Digital Therapeutics' have been clinically validated and approved by the U.S. Food and Drug Administration as therapeutic medical devices usually as a complement to standard therapy. Artificial intelligence (AI) has been utilized in diagnostics and treatment. In particular, AI has shown promising capability in image interpretation and prediction.

J Sleep Med 2019;16(2):71-74

\section{서 론}

모바일을 비롯한 디지털 기술의 발전은 우리 삶 곳곳에서 큰 변화를 가져오고 있다. 의료 역시 마찬가지로 많은 제품 들이 기존 의료에서 제공하지 못했던 새로운 가치를 제공하 고 있다. 보수적인 의료계의 속성상 아직 혁신적인 변화를 가져오지는 못하는 경우가 많지만 기술 발전 속도가 빨라지 고 임상 현장에 실제 도움을 줄 수 있을 만한, 검증된 제품의 형태로 만들어지는 경우가 늘어나고 있다. 의료의 주요 영역 에서 디지털 헬스케어가 활용되고 있는 현황을 다루면서 수 면의학에 적용되는 사례에 대해 살펴보고자 한다.

\section{본 론}

\section{일상 생활 속에서 검사를 하고 진단받는다}

센서 기술이 발달하고 이를 통해 수집한 데이터를 스마트 폰을 통해서 빠르게 분석할 수 있게 되면서 과거 병원에 가

This is an Open Access article distributed under the terms of the Creative Commons Attribution Non-Commercial License (https://creativecommons.org/licenses/by-nc/4.0) which permits unrestricted non-commercial use, distribution, and reproduction in any medium, provided the original work is properly cited.
서야 할 수 있었던 검사를 편한 시간과 장소에서 받는 것이 가능해지고 있다. 특히 스마트폰의 보급은 큰 의미를 가지는 데 과거에는 진단 장비가 독자적으로 데이터를 처리해야 했 기 때문에 구조가 복잡하고 가격이 비싼 경우가 많았다. 누 구나 스마트폰이라는 고성능 컴퓨터를 항상 가지고 다니는 지금의 상황에서는 스마트폰과 연결하여 그 연산 능력을 활 용할 수 있기 때문에 간단하고 값싼 장비를 만드는 것이 용 이해졌다. 이로 인해 과거 병원 내에서, 의료인의 감시하에 서만 이루어지던 검사, 측정을 일상 생활 속에서 간편하게 실시하는 것이 가능해지고 있다.

대표적인 제품이 스마트 워치와 같은 웨어러블 제품이다. 처음에는 걸음 수를 측정하는 수준에 머물렀던 웨어러블은 센서의 발전과 함께 심박수, 심전도를 측정하는 수준까지 발 전했다. Apple을 비롯한 주요 회사들은 심전도 측정에 더해 서 심방 세동과 같은 다빈도 부정맥을 진단하는 알고리즘을 개발하여 제품에 탑재하고 있다. 이외에도 폐활량, 뇌파, 심 지어 태아의 움직임 등 병원 밖에서 측정하기 힘들다고 보았 던 것들을 일상 생활 속에서 측정하도록 해주는 제품들이 나 오고 있다.

스마트폰에 탑재된 센서의 성능이 좋아지면서 별도의 장 
비 없이 스마트폰만으로 진단하려는 시도도 이루어지고 있 다. ResApp(Brisbane, Australia) 회사는 기침 소리와 별도로 입력한 증상을 분석하여 주요 호흡기 질환을 진단하는 앱을 개발하고 있으며 이미 유럽 규제 기관의 승인을 받았다. ${ }^{1}$ 특 히 이 회사는 스마트폰 마이크를 통해 수면 중 만들어지는 소리를 분석하여 수면 무호흡을 진단하기 위한 시도를 하고 있다. 당연히 정확성이 떨어지겠지만, 수면 무호흡이 있다는 것을 모르고 있거나 의심이 된다고 해도 입원해서 수면다원 검사를 받기 힘든 사람들이 스크리닝 용도로 사용하는 것은 가능해 보인다. Somnarus(Mountain View, CA, USA) 회사 는 Somna patch를 개발했는데 이는 1회용 수면무호흡검사 장비이다. 이마와 코에 패치 형태의 제품을 부착해서 사용할 수 있다. 병원에서 할 수 있는 검사에 비해서 한계가 있지만 진단에 도움이 될 만한 정보를 얻을 수 있다. 이 회사는 의료 기기 회사인 Philips에 인수되었다.

새로운 진단 장비를 만들 수 있게 된 것과는 별개로 혈당 계, 혈압계와 같이 스마트폰 시대 이전부터 사용했던 제품들 도 스마트폰과 데이터를 연동할 수 있게 되면서 데이터를 더 욱 효율적으로 관리하는 것이 가능해졌다. 이 부분은 간과하 기 쉬운데 기존 진료 환경에서 당뇨 환자가 혈당계를 사용하 는 상황을 생각해보면 그 중요성을 알 수 있다. 의사는 당뇨 환자에게 혈당계를 사용하도록 하면서 당뇨 수첩에 수치를 적어서 가져오도록 권한다. 하지만 많은 환자들이 의사의 처 방만큼 충분히 혈당 검사를 하지 않고 있으며 검사를 해도 당뇨 수첩에 적지 않는 경우가 많으며, 기껏 수첩에 적어 놓 고서 수첩을 갖고 오지 않는 경우도 많다. 당뇨 수첩을 갖고 오지 않는 환자는 있어도 스마트폰을 가져오지 않는 환자는 없기 때문에, 환자가 혈당을 측정했고 그 데이터가 스마트폰 에 있는 앱으로 연동되었다면 의사가 그 데이터를 보고 치료 방침을 결정할 수 있을 것이다. 스마트폰과 함께 측정해 놓 고도 쓰이지 못하던 의료 데이터를 효과적으로 활용하는 것 이 가능해진다.

\section{일상 생활 속에서 질병을 관리한다}

이와 같이 다양한 하드웨어 제품을 통해서 손쉽게 질병 정 보를 수집할 수 있게 되면서 이를 활용해서 질병을 관리, 치 료하는 것이 가능해지고 있다. 치료 영역의 디지털 헬스케어 에서는 최근 디지털 신약(digital therapeutics)이라는 개념이 널리 퍼지고 있다. 아직 누구나 동의하는 정의는 없지만 대 략 앱이나 게임, 가상현실 등과 같은 디지털 제품 가운데 질 병을 관리하거나 치료하는 목적의 제품으로 특히, 임상 시험 을 통해서 입증된 것을 의미한다고 볼 수 있다.

iPhone이 출시되고 앱 마켓이 생겨난 이후 많은 헬스케어
앱이 만들어졌다. 벌써 10여 년 전에 WellDoc(Columbia, MD, USA) 회사는 U.S. Food and Drug Administration (FDA)의 승인을 받은 당뇨 관리 앱을 출시했다. 이외에도 많은 앱들이 독자적으로 혹은 하드웨어와 연계되는 형태로 $\mathrm{FDA}$ 로부터 의료기기 승인을 받았다. 최근에는 디지털 신약 이라는 개념이 각광을 받고 있다. 그 시작이라고 볼 수 있는 것이 Pear therapeutics(Boston, MA, USA) 회사에서 만든 약물 중독 치료 앱으로 $\mathrm{FDA}$ 승인을 받은 reSET이다. 기존 앱과 reSET의 가장 큰 차이는 FDA 허가 사항에 '치료 목적' 이 포함되어 있다는 점이다. 기존 앱들은 임상 시험을 통해서 질병 관리에 유효한 성과를 거두었음을 입증했음에도 불구 하고 데이터 관리 등 치료 이외의 목적으로 $\mathrm{FDA}$ 로부터 승인 을 받은 반면 reSET의 승인 내용에는 치료 목적이 명시되어 있다는 점이 다르다. Pear therapeutics는 reSET에 이어 마약 중독 치료 앱인 reSET-O에 대해서도 FDA 승인을 받으면 서 이 분야를 이끌어가고 있다. 현재까지 승인받은 약물들은 기존의 상담 치료 혹은 약물 치료를 보조하는 용도로 승인되 었으며 아직 단독 치료 용도로 승인을 받은 제품은 없다. 이 외에도 여러 회사들이 수면장애, 우울증, 불안장애 등을 대상 으로 한 디지털 신약을 개발하고 있다. 수면장애와 관련해서 는 Pear therapeutics, Click therapeutics(New York, NY, $\mathrm{USA}$ ), Cognoa(Palo Alto, CA, USA) 회사가 개발 중이며 Pear therapeutics는 Somryst라는 제품을 FDA 승인 신청한 상태이다. ${ }^{2}$

앱 기반의 제품 이외에 하드웨어와 연동되는 형태의 제품 도 다양하게 나오고 있다. 혈당계와 같은 진단 장비나 약물 복용 여부를 감시할 수 있는 스마트 센서와 연동되는 형태가 많다. 약물 복용을 감시하는 스마트 센서의 경우 주사기, 흡 입기에 센서를 부착해서 약물 사용 여부를 확인해 준다. 여 기서 한발 더 나아가 알약에 센서를 탑재하는 경우도 있다. Proteus(Redwood City, CA, USA) 회사는 스마트 알약 센서 를 만드는데 이 센서를 탑재한 최초의 약물이 2017년 11월 에 FDA 승인을 받았다. Abilify Mycite라는 이름의 약으로 조현병 치료제인 Abilify에 센서를 탑재한 형태이며 환자가 약을 먹었는지 여부를 확인해 준다. ${ }^{3}$ 약물 가격이 비싸서 확 산되지는 못하고 있지만 생각하는 것보다 기술이 빠르게 발 전한다는 것을 보여주는 사례이다.

지금까지 살펴본 사례에서 알 수 있는 것처럼 기존 치료를 완전히 대체할 수 있는 제품은 아직 없다. 현실적으로 의사 혹은 기존 치료법을 대체하기보다는 의사가 시행하고 있는 치료법을 보조하는 용도로 사용될 가능성이 높다. 이는 의사 의 진료를 침해한다기보다는 원하는 만큼 의사의 도움을 받 기가 힘든 환자들이 도움을 받을 수 있는 유효한 도구로 볼 
수 있을 것이다.

\section{인공지능을 진료에 활용한다}

알파고가 이세돌 9단을 이기면서 많은 사람이 인공지능이 먼 미래의 이야기가 아님을 실감하게 됐다. 의료계 역시 마 찬가지였다. 각종 매체의 전망을 근거로 인공지능이 머지않 아 의사를 대체할지 모른다는 우려가 나오기도 했고 대체하 기보다는 의사가 도움을 받을 수 있는 좋은 도구가 될 것이 라는 지적도 많았다. 다음과 같은 3 가지 영역을 중심으로 인 공지능이 활용될 것으로 보인다.

\section{임상 의사 결정 지원}

인천 길병원을 시작으로 여러 병원들이 도입하면서 유명 해진 IBM의 인공지능 Watson의 경우 전문가들이 알고 있는 규칙을 학습하고 이를 의료 현장에 적용하는 것이다. 잘 알 려진 것처럼 Watson은 의학 교과서와 저널 등을 공부한 후 의사들이 진료하는 과정을 학습하는 과정을 거쳤다. 이후 Watson for Oncology라는 이름으로 암 환자의 치료 방침 결 정에서 활용되고 있다. 예를 들어 암 환자의 의무기록과 검 사 결과 데이터를 보고 최적의 항암 치료 방법을 제시해 줄 수 있다. Watson은 기대에 미치지 못한다는 평가를 받고 있 는데 의료에서의 의사 결정 과정이 복잡하다는 것을 보여준 다고 할 수 있다. 현재 수준의 인공지능으로는 다양한 데이 터를 바탕으로 한 임상 의사 결정 지원은 쉽지 않아 보인다.

\section{의료 이미지 판독}

진료 현장에 적용하는 것에 비해서 단일한 데이터를 다루 는 경우는 학습 및 진료 현장에 적용하는 과정이 더 수월할 수 있다. 이런 이유로 의료 영상을 비롯한 이미지 분석에 대 한 인공지능의 적용이 활발해지고 있다. 의료 영상 판독에 컴퓨터를 활용하려는 시도는 과거부터 있었다. 컴퓨터 자동 진단 시스템(computer-aided detection)이라는 이름으로 영 상 진단 교과서에 나오는 진단 규칙을 컴퓨터에 학습시켜서 진단에 활용하고자 했다. 하지만 진단 성과가 좋지 못한 경우 가 많아서 진료 현장에서 제한적으로 활용됐다. 인공지능의 한 종류인 딥러닝(deep learning)의 성능이 좋아지기 시작하 면서 진단의 정확도를 높여줄 수 있을 가능성이 커지고 있다.

딥러닝은 간단히 말하자면 서로 다른 것으로 분류된 데이 터를 학습해 새로운 데이터를 그렇게 분류할 수 있도록 학습 하는 방법을 의미한다. 예를 들어 고양이가 들어가 있는 사 진을 다량으로 학습시킨 후 새로운 동물 사진을 보여주면 고 양이 여부를 판단할 수 있다. 기존의 방식이 고양이의 특징 을 하나하나의 규칙으로 만들어서 컴퓨터를 학습시키는 것
이었다면 딥러닝은 컴퓨터가 알아서 고양이의 특징을 학습 하도록 하는 것이라고 할 수 있다.

현재 딥러닝은 의료 영상을 포함해 이미지로 나타나는 데 이터를 분석하는 데 많이 사용된다. 대표적인 것이 의료 영 상 진단 분야이다. 국내외에서 스타트업을 포함한 많은 회사 들이 딥러닝을 의료 영상 분석에 적용하기 위해서 노력하고 있다. Google은 이 분야에서 지속적인 연구를 해오고 있으며 알파고로 유명한 딥마인드(DeepMind)를 망막 안저 사진 분석 에 적용하여 그 결과를 2016년 11월 JAMA에 게재한 바 있다. ${ }^{4}$

영상의학계에서는 과거 컴퓨터 자동 진단 시스템이 기대 에 미치지 못하는 성과를 냈다는 점 때문에 딥러닝 기반의 영상 판독 시스템 역시 영상의학과 의사의 수준을 뛰어넘기 어렵다고 보는 의견도 있었다. 하지만 딥러닝의 특성상 충분 한 데이터를 학습시킬 수 있다면 의사가 지식으로 표현하지 는 못하지만 진단에 활용되는 암묵지까지 학습할 수 있다. 장기적으로 기존 진단 시스템을 뛰어넘을 가능성이 높으며 실제 여러 회사가 내놓는 성과를 보면 웬만한 의사 수준에 육박하는 경우가 많다. 특히 2018년 4월에는 독자적인 진단 능력을 인정받은 영상 판독 인공지능이 나오기도 했다. IDx (Coralville, IA, USA) 회사에서 개발한 IDx-DR이라는 인공 지능으로 당뇨병 환자에서 당뇨성 망막병증을 선별 검사하 는 용도의 의료기기로 FDA 허가를 받았다. ${ }^{5}$ 기존의 의료 인 공지능은 의사가 효율적으로 일하는 것을 도와주거나 의사 가 진단하는 것을 보조해주는 용도로 허가를 받은 반면 이 제품은 독자적으로 의미 있는 의사 결정을 내릴 수 있다는 것 을 인정받았다. 확진이 아닌 선별 검사라는 점에서 한계가 있 지만 의료에서 인공지능이 발전하고 있음을 보여주는 상징 적인 사건이라고 할 수 있다.

이렇게 의료에서 딥러닝 기술을 적용하고자 노력하는 회 사들은 의료 영상 분야에 집중하는 경우가 많다. 하지만 이 미지 형태로 저장되는 검사 결과들은 모두 그 분석 대상이 될 수 있다. 병리 슬라이드 분석, 심전도, 뇌파, 근전도 검사 등이 모두 대상이 될 수 있다.

\section{새로운 지식 발견}

세 번째 영역은 어떤 의료적인 사실과 연관된 데이터 또는 알고리즘을 찾아내는 것이다. 예를 들어 평소에 수집한 데이터 를 분석해 질병이 발생하기 전에 나타나는 변화를 발견해내는 경우가 있다. 2016년 1월 IBM과 의료기기 회사인 Medtronic (Minneapolis, MN, USA)이 지속형 혈당 측정계가 측정한 혈당 데이터를 분석해서 최대 3 시간 전에 저혈당 발생을 예 측할 수 있는 알고리즘을 개발했다고 발표한 것이 대표적인 사례이다. 지금까지는 어지러움 등 증상이 발생한 다음에야 
조치할 수 있었는데 이 알고리즘을 사용하면 미리 대처할 수 있을 것이다. 이 사례를 보면 지속적으로 측정한 데이터를 분 석하면 과거 알지 못했던, 또는 어떤 위험한 이벤트가 발생 하기 전에 생기는 변화를 미리 잡아내는 것이 충분히 가능해 보인다. IBM과 Medtronic은 이후 저혈당 발생 예측 알고리 즘을 탑재한 앱 Sugar. $\mathrm{IQ}^{\mathrm{TM}}$ 을 개발했다. 또한 지속형 혈당 측 정계와 인슐린 펌프를 결합한 제품에 이와 같은 알고리즘을 적용하여 혈당을 알아서 조절해 줄 수 있는 '인공 췌장'으로 진화, 발전시키기도 했다.

진단 대상이 되는 사건이 발생하기 전부터의 데이터를 충 분히 모을 수 있다면 이런 식의 예측은 충분히 가능하다. 중 환자실에서 사망이나 치명적인 부정맥 발생 전 데이터를 모 으고 이를 분석해서 중요 사건 발생을 예측하는 것이 가능하 다. 국내 회사와 병원이 이를 연구하여 결과를 발표하기도 하였다.

\section{결 론}

새로운 기술과 함께 의료는 더 크게 발전할 것이다. 다만, 의료계에서 변화가 도입되는 속도가 느리다는 점은 감안해 야 한다. 기본적으로 보수적인 분야이기도 하지만 제품 사용 자와 제품 사용을 결정하는 사람(병원, 의사), 지불자(보험회 사)가 모두 다르며 셋 모두 막강하다는 특징이 있기 때문에 혁신적인 변화가 일어나기 쉽지 않기 때문이다. 그럼에도 기 술의 변화가 우리의 삶을 바꾼다는 큰 흐름에는 변화가 없을
것이며 이를 통해 우리의 건강은 더욱 증진될 것이다.

\section{Acknowledgments}

None.

\section{Conflicts of Interest}

The author has no potential conflicts of interest to disclose.

\section{ORCID iD}

Chiweon Kim

https://orcid.org/0000-0003-2176-3130

\section{REFERENCES}

1. ResApp Health. ResApp receives CE mark approval for smartphonebased diagnostic test for adult and paediatric respiratory disease. ResApp Health [cited 2019 Sep 26]. URL: https://www.resapphealth.com. au/resapp-receives-ce-mark-approval-for-smartphone-based-diagnostic-test-for-adult-and-paediatric-respiratory-disease/. Accessed 2019 Oct 15.

2. Chung JY. Digital therapeutics and clinical pharmacology. Transl Clin Pharmacol 2019;27:6-11.

3. Miliard M. Otsuka, Proteus finally win FDA approval for sensorequipped Abilify. Mobi health news [cited 2017 Nov 14]. URL: https:// www.mobihealthnews.com/content/otsuka-proteus-finally-win-fdaapproval-sensor-equipped-abilify. Accessed 2019 Oct 15.

4. Gulshan V, Peng L, Coram M, et al. Development and validation of a deep learning algorithm for detection of diabetic retinopathy in retinal fundus photographs. JAMA 2016;316:2402-2410.

5. U.S. Food and Drug Administration. FDA permits marketing of artificial intelligence-based device to detect certain diabetes-related eye problems. U.S. Food and Drug Administration [cited 2018 Apr 11]. URL: https://www.fda.gov/news-events/press-announcements/fdapermits-marketing-artificial-intelligence-based-device-detect-certaindiabetes-related-eye. Accessed 2019 Oct 15. 